\title{
PREDIKSI MODEL PENETAPAN KADAR FLAVONOID TOTAL PADA EKSTRAK Abelmoschus manihot L. MENGGUNAKAN SPEKTROSKOPI IR YANG DIKOMBINASIKAN DENGAN KEMOMETRIK
}

\author{
Juliandro Matsuzaki Fangohoy ${ }^{1)}$, Sri Sudewi ${ }^{1)}$, Adithya Yudistira ${ }^{1)}$ \\ ${ }^{1)}$ Program Studi Farmasi FMIPA UNSRAT Manado, 95115
}

\begin{abstract}
This study aims to determine the validation of IR spectroscopy method in determining the total flavonoid level in Abelmoschus manihot L., can meet the requirements and can be applied. The method for determining the total flavonoid content model using a combination of IR Spectroscopy and Chemometrics Partial Least Square Regression (PLSR). The calorimetrics method was used to determine the total flavonoid content in the green gedi leaves axtracts onn eight samples of growth where Bitung Was 2.64 $\mathrm{mg}$ QE/g extract \pm 0.035 , Minahasa Selatan is $1.91 \mathrm{mg}$ QE/g extract \pm 0.027 , Kotamobagu is $4.84 \mathrm{mg}$ $Q E / g$ extract \pm 0.03 , Minahasa Utara is $4.40 \mathrm{mg}$ QE/g extract \pm 0.091 , Manado is $3.45 \mathrm{mg} Q E / g$ extract \pm 0.012 , Minahasa Tenggara is $1.72 \mathrm{mg} Q E / g$ extract \pm 0.006 , Minahasa is $3.67 \mathrm{mg} \mathrm{QE} / \mathrm{g}$ extract \pm 0.033 , Tomohon is $3.40 \mathrm{mg} Q E / g$ extract \pm 0.003 . This combination is involves involving $x$-variables (FTIR measurement results) and y-variables (data from the results of the calorimetric method analysis). Error value [standard error calibration $(S E C=0.003)$, standard error of prediction $(S E P=0.052)$ ] and cslibration $r$ value 0.999, and $r$ validation 0.975 .
\end{abstract}

Keywords: Flavonoids, Green Gedi Leaves, FTIR Spectrofotometry, UV-VIS Spectrofotometry, Chemometrics

\begin{abstract}
ABSTRAK
Penelitian ini bertujuan untuk mengetahui Validasi Metode Spektroskopi IR Pada Penetapan kadar Flavonoid Total pada Abelmoschus manihot L Dapat Memenuhi Persyaratan dan Dapat di Aplikasikan. Metode penentuan model kandungan flavonoid total menggunakan kombinasi Spektroskopi IR dan Kemometrik Partial Least Square Regression (PLSR). Metode Kalorimetrik digunakan untuk mengetahui kandungan Flavonoid Total pada pada Ekstra Daun Gedi Hijau pada 8 sampel tempat tumbuh yaitu Bitung sebesar $2.64 \mathrm{mg} \mathrm{QE} / \mathrm{g}$ ekstrak \pm 0.035 , Minahasa Selatan sebesar $1.91 \mathrm{mg}$ QE/g ekstrak \pm 0.027 , Kotamobagu sebesar $4.84 \mathrm{mg}$ QE/g ekstrak \pm 0.03 , Minahasa Utara sebesar $4.40 \mathrm{mg}$ QE/g ekstrak \pm 0.091, Manado sebesar $3.45 \mathrm{mg}$ QE/g ekstrak \pm 0.012 , Minahasa Tenggara sebesar $1.72 \mathrm{mg} \mathrm{QE} / \mathrm{g}$ ekstrak \pm 0.006 , Minahasa sebesar $3.67 \mathrm{mg} \mathrm{QE} / \mathrm{g}$ ekstrak \pm 0.033 , Tomohon sebesar $3.40 \mathrm{mg} \mathrm{QE} / \mathrm{g}$ ekstrak \pm 0.003 . Kombinasi ini melibatkan melibatkan variabel $\mathrm{x}$ (hasil pengukuran FTIR) dan variabel $\mathrm{y}$ (data hasil analisis metode Kalorimetrik). Nilai kesalahan (standar error calibration (SEC $=0.003$ ), standard error of prediction ( $\mathrm{SEP}=0.052)$ ) dan nilai $r$ kalibrasi 0.999 , serta $r$ validasi 0.975 .
\end{abstract}

Kata Kunci: Total Flavonoid, Daun Gedi Hijau, Spektrofotometri FTIR, Spektrofotometri UV-VIS, Kemometrik. 


\section{PENDAHULUAN}

Gedi hijau (Abelmoschus manihot L.) merupakan salah satu tumbuhan dari suku Malvaceae umum ditanam dan dimanfaatkan oleh masyarakat di Sulawesi Utara khususnya Manado. Masyarakat Manado sendiri biasa memanfaatkan Gedi hijau (khususnya bagian daun) sebagai bahan makanan yang dikenal sebagai Bubur Manado (Tinutuan), yang merupakan salah satu makanan khas dari Manado (Mamahit dan Sukarno, 2010).

Senyawa flavonoid merupakan senyawa polifenol yang mempunyai 15 atom karbon yang tersusun dalam konfigurasi $\mathrm{C}_{6^{-}}$ $\mathrm{C}_{3}-\mathrm{C}_{6}$, yaitu dua cincin aromatik yang dihubungkan oleh 3 atom karbon yang dapat atau tidak dapat membentuk cincin ketiga. Golongan flavonoid dapat digambarkan sebagai deretan senyawa $\mathrm{C}_{6}-\mathrm{C}_{3}-\mathrm{C}_{6}$, artinya kerangka karbonnya terdiri atas dua gugus $\mathrm{C}_{6} \quad$ (cincin benzena tersubstitusi) disambungkan oleh rantai alifatik tiga karbon (Robinson, 1991).

Analisis kuantitatif senyawa flavonoid total dengan menggunakan spektrofotometri UV-Vis dilakukan untuk mengetahui seberapa besar kadar flavonoid total yang terkandung pada ekstrak etanol daun gedi hijau (Abelmoschus manihot L.). Analisis flavonoid dilakukan dengan menggunakan Spektrofotometri UV-Vis karena flavonoid mengandung sistem aromatik yang terkonjugasi sehingga menunjukkan pita serapan kuat pada daerah spektrum sinar ultraviolet dan spektrum sinar tampak (Harborne, J.B 1987).

Spektrofometer inframerah tertransformasi Fourier (Fourier transformed infrared spectrophotometer, FTIR) merupakan suatu metode yang dapat mengukur secara cepat contoh tanpa merusak dan mampu menganalisis beberapa komponen secara serentak. Akan tetapi, Penggunaan FTIR dalam analisis tumbuhan masih terbatas karena matriks dan spektrum yang dihasilkan cukup kompleks. Dukungan kemometrik memperluas potensi spektroskopi FTIR sebagai metode alternatif untuk menganalisis komponen tumbuhan. (Wold et al., 2001).

Berdasarkan hal-hal diatas maka mendorong penulis melakukan penelitian yang lebih intensif untuk mengetahui kadar flavonoid total Abelmoschus manihot $L$. menggunakan Spektrofometer inframerah tertransformasi Fourier (Fourier transformed infrared spectrophotometer, FTIR) karena metode ini merupakan suatu metode yang dapat mengukur secara cepat contoh tanpa merusak dan mampu menganalisis beberapa komponen secara serentak,

\section{METODELOGI}

\section{PENELITIAN}

\section{Waktu dan Tempat Penelitian}

Penelitian ini dilaksanakan pada bulan November 2018 sampai Mei 2019 di Laboratorium Penelitian Farmasi Lanjutan, Program Studi Farmasi, Fakultas Matematika dan Ilmu Pengetahuan Alam, Universitas Sam Ratulangi Manado

\section{Bentuk Penelitian}

Penelitian ini dilakukan dengan menggunakan metode eksperimental yang artinya penelitian ini dilakukan untuk mengetahui akibat yang ditimbulkan dari 
suatu perlakuan yang diberikan secara sengaja oleh peneliti.

\section{Alat dan Bahan}

a. Alat

Alat-alat ukur analitis yang digunakan untuk penelitian ini adalah Spektrofotometri UV-VIS (Shimadzu 00780), Komputer pengolah data (Acer Aspie ES 11), Alat-alat gelas, Vortex (Mixer Hwashin), toples, Blender (Phillips), Water Bath, rotary shacker.

\section{b. Bahan}

Bahan-bahan yang dipakai dalam penelitian ini adalah simplisia kering daun Gedi dari 8 tempat tumbuh yang berbeda yaitu Minahasa, Minahasa Utara, Minahasa Selatan, Minahasa Tenggara, Tomohon, Manado, Bitung dan Kotamobagu . Etanol p.a, etanol $96 \%$, almunium klorida $\left(\mathrm{AlCl}_{3}\right)$ (Merck), asam asetat $\left(\mathrm{CH}_{3} \mathrm{COOH}\right)$ (Merck), kuersetin p.a, pelarut n-heksana (Merck), etil asetat (Merck), dan aquadest (Merck).

\section{Prosedur Penelitian}

\section{Pengambilan Sampel}

Sampel daun Gedi Hijau (Abelmoschus manihot L.) diambil dari 8 tempat tumbuh yang berbeda yaitu Minahasa, Minahasa Utara, Minahasa Selatan, Minahasa Tenggara, Tomohon, Manado, Bitung dan Kotamobagu. Selanjutnya setiap sampel daun gedi hijau (Abelmoschus manihot L.) dibuat menjadi bentuk simplisia. Kemudian setiap sampel dari masing-masing kota dibuat ekstrak dengan menggunakan metode maserasi.

\section{Ekstraksi}

Sebanyak 250 gram serbuk simplisia dimasukkan ke dalam toples $500 \mathrm{~mL}$ dan kemudian ditambahkan etanol $96 \%$. Ekstraksi dilakukan dengan cara maserasi selama 3 hari dan pengadukan dibantu dengan alat rotary shacker. Ekstrak hasil maserasi kemudian diuapkan dengan Water Bath hingga terbentuk ekstrak kental.

\section{Pembuatan Latrutan Baku Kuersetin}

Dibuat larutan induk 1000 ppm dengan cara menimbang dengan seksama 10 mg kuersetin p.a dan dilarutkan dengan etanol p.a $10 \mathrm{~mL}$. Kemudian dibuat larutan standar kuersetin 10; 20; 30; 40; 50 ppm dari pengenceran larutan baku kuersetin 1000 ppm.

\section{Penentuan Panjang Gelombang Maksimum Kuersetin}

Panjang gelombang maksimum ditentukan dengan cara membuat larutan standar kuersetin 40 ppm kemudian sebanyak $1 \mathrm{~mL}$ larutan kuersetin $40 \mathrm{ppm}$ tersebut direaksikan dengan $1 \mathrm{~mL} \mathrm{AlCl}_{3} 2 \%$ di dalam tabung reaksi. Kemudian ditambahkan $8 \mathrm{~mL}$ asam asetat 5\% ke dalam larutan dan dilakukan pembacaan pada rentang panjang gelombang 400-500 nm menggunakan Spektrofotometer UV-Vis.

\section{Penetapan Operating Time Kuersetin}

Penentuan operating time dilakukan dengan mengambil sebanyak $1 \mathrm{~mL}$ larutan kuersetin 20 ppm dimasukkan dalam tabung reaksi, lalu direaksikan dengan $1 \mathrm{~mL} \mathrm{AlCl}_{3}$ $2 \%$, dan ditambahkan $8 \mathrm{~mL}$ asam asetat $5 \%$ ke dalam larutan. Larutan diukur absorbansinya pada panjang gelombang 
maksimum yang telah diperoleh dengan interval waktu 60 menit sampai diperoleh absorbansi yang stabil (Sukmawati, 2014).

\section{Pembuatan Kurva Baku Kuersetin}

Pembuatan kurva baku kuersetin dilakukan dengan cara membuat larutan baku kuersetin 1000ppm, lalu dibuat larutan dengan seri konsentrasi $10 ; 20 ; 30 ; 40 ; 50$ ppm kemudian dipipet $1 \mathrm{ml}$ lalu ditambahkan $1 \mathrm{ml}$ aluminium (III) klorida 5\%, $1 \mathrm{ml}$ larutan $\mathrm{CH}_{3} \mathrm{COOH} 5 \%$, Setelah itu diinkubasi selama 20 menit, absorbansi dari larutan pembanding diukur menggunakan spektrofotometer UV Vis pada panjang gelombang maksimum.

\section{Penentuan Kandungan Total Flavonoid Ekstrak Daun Gedi}

Sampel ekstrak etanol daun gedi hijau 1000 ppm dipipet sebanyak $1 \mathrm{~mL}$ ditambahkan dengan volume aluminium klorida $\left(\mathrm{AlCl}_{3}\right)$ hasil optimasi dengan konsentrasi dari hasil optimasi yang paling optimal. Tambahkan volume hasil optimasi asam asetat $\left(\mathrm{CH}_{3} \mathrm{COOH}\right)$ dengan konsentrasi hasil optimasi yang paling optimal. Campuran dikocok homogen lalu dibiarkan selama waktu inkubasi yang paling optimal dari hasil optimasi waktu inkubasi. Kemudian diukur serapannya menggunakan spektrofotometer UV-Vis pada panjang gelombang maksimum. Penentuan nilai flavonoid akhir dilakukan berdasarkan formula yang dikembangkan oleh Pan et al. (2012), yaitu:

Flavonoid Total $=\left(\frac{\mathrm{m}}{\mathrm{g}}\right)=\frac{\mathrm{Y} \times \mathrm{N} \times \mathrm{V}}{\mathrm{W}}$
Keterangan :

$\mathrm{Y}=$ konsentrasi flavonoid contoh yang

dihitung dengan menggunakan persamaan kurva standard $\left(\mathrm{mg} \mathrm{g}^{-1}\right)$

$\mathrm{N}=$ Faktor pengenceran .

$\mathrm{V}=$ volume Sampel $(\mathrm{mL})$.

$\mathrm{W}=$ berat Sampel $(\mathrm{g})$.

\section{Pembuatan spektrum FTIR}

Sebanyak $0.5 \mathrm{mg}$ serbuk daun Gedi dicampurkan dengan $180 \mathrm{mg} \mathrm{KBr}$, dihomogenisasi. Pengukuran spektrum FTIR dilakukan pada daerah IR tengah (4000- 400 $\mathrm{cm}^{-1}$ ) dengan melibatkan pengontrol kerja berupa personal komputer yang dilengkapi perangkat lunak OPUS versi 4.2. Spektrum dihasilkan dengan kecepatan 32 detik dan resolusi $4 \mathrm{~cm}-1$. Tampilan data spektrum akan menampilkan jumlah titik serapan kemudian diubah ke dalam format DPT (data point table) untuk keperluan pengolahan data. Data ini dapat dibuka dengan program Microsoft Excel. Selanjutnya data jumlah titik serapan yang ditampilkan (telah dihilangkan serapan $\mathrm{CO}_{2}$ nya pada $2399-2252 \mathrm{~cm}^{-1}$ ) diolah dengan program Mini Tab yang dijalankan dengan sistem operasi Microsoft Windows 10.

\section{Analisis Data}

Model kalibrasi multivariat dibuat dengan program Mini Tab menggunakan metode regresi PLS. Pembentukan model prediksi flavonoid total dilakukan oleh PLS dengan melibatkan variabel $\mathrm{x}$ (hasil pengukuran FTIR) dan variabel y (data hasil analisis metode $\mathrm{AlCl} 3$ ). Kalibrasi dan validasi model diolah dengan teknik validasi silang. Keakuratan model dapat dilihat pada nilai korelasi atau koefisien determinasi dan 
nilai kesalahan yang dihasilkan. Model dapat digunakan bila memiliki nilai kesalahan (standar error calibration SEC, standard error of prediction SEP) rendah dan nilai korelasi atau koefisien determinasinya tinggi.

\section{HASIL DAN PEMBAHASAN Hasil Ekstraksi}

Setiap sampel sebanyak 250 gram serbuk simplisia daun gedi hijau dimasukkan ke dalam toples $500 \mathrm{ml}$ dan di tambahkan etanol. Ekstraksi dilakukan dengan cara maserasi selama 24 jam menggunakan alat bantu pengaduk (rotary shacker). kemudian disaring dan didapatkan filtrat. Filtrat yang diperoleh akan diuapkan dengan rotary evaporator.

Berdasarkan hasil ekstraksi 250 gram daun gedi hijau maka diperoleh jumlah hasil rendemen dari masing-masing ekstrak adalah kota Bitung sebesar 5,50\%, Minahasa Selatan sebesar 5,80\%, Kotamobagu sebesar 5,25\%, Minahasa Utara sebesar 5,34\%, Manado sebesar 6,59\%, Minahasa Tenggara sebesar 7,23\%, Minahasa sebesar 7,34\% dan Kota Tomohon sebesar 5,63\%.

\section{Penentuan Panjang Gelombang Maksimum Kuersetin}

Pada penelitian ini penentuan panjang gelombang maksimum dilakukan dengan menggunakan Spektrofotometer UV-Vis pada daerah panjang gelombang 400-500 $\mathrm{nm}$ dan konsentrasi yang dipakai adalah $40 \mathrm{ppm}$ sehingga diperoleh panjang gelombang $415 \mathrm{~nm}$.

Tujuan penentuan panjang gelombang maksimum agar mengetahui daerah serapan yang dapat dihasilkan berupa nilai absorbansi dari larutan baku kuersetin yang diukur serapannya menggunakan alat spektrofotometer UV-Vis pada rentang panjang gelombang 400-500 nm. Data hasil panjang gelombang maksimum dapat dilihat pada gambar 1.

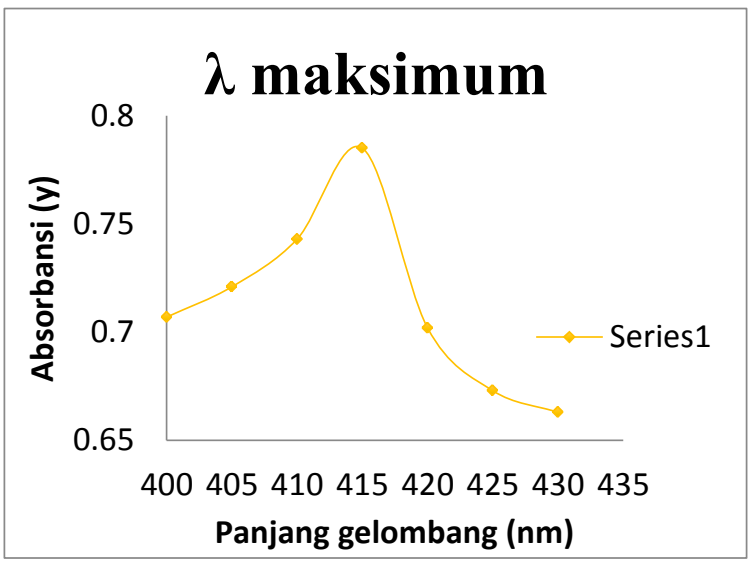

Gambar 1. Kurva Panjang gelombang Maksimum Kuersetin

\section{Penentuan Operating Time}

Dari hasil pengukuran Operating Time, didapatkan bahwa absorbansi stabil pada menit ke-1 sampai dengan menit ke-20. Hal ini menunjukkan bahwa berdasarkan kestabilannya waktu optimal untuk pembacaan absorbansi adalah pada menit ke-1 sampai menit ke-20. Penentuan operating time perlu dilakukan untuk mengetahui waktu kestabilan optimal. Operating time ditentukan dengan mengukur absorbansi pada panjang gelombang maksimum dari data yang telah dihasilkan pada penentuan panjang gelombang maksimum yaitu $415 \mathrm{~nm}$ dengan konsentrasi yang digunakan adalah 20 ppm dengan rentang waktu 1-20 menit dengan hasil absorbansi yaitu 0,42 . 


\section{Kurva Kalibrasi Kuersetin dan Lineritas}

Berdasarkan hasil pembuatan kurva kalibrasi dengan menggunakan metode Spektrofotometri yang menghubungkan konsentrasi dengan absorbansi, diperoleh persamaan linear $\mathrm{y}=0.135 \mathrm{x}-0,015$ dengan koefisien korelasi $\mathrm{r}=0,988$. Hasil koefisien korelasi diatas telah memenuhi kriteria penerimaan yaitu $\geq 0,98$ (Hermita, 2004).

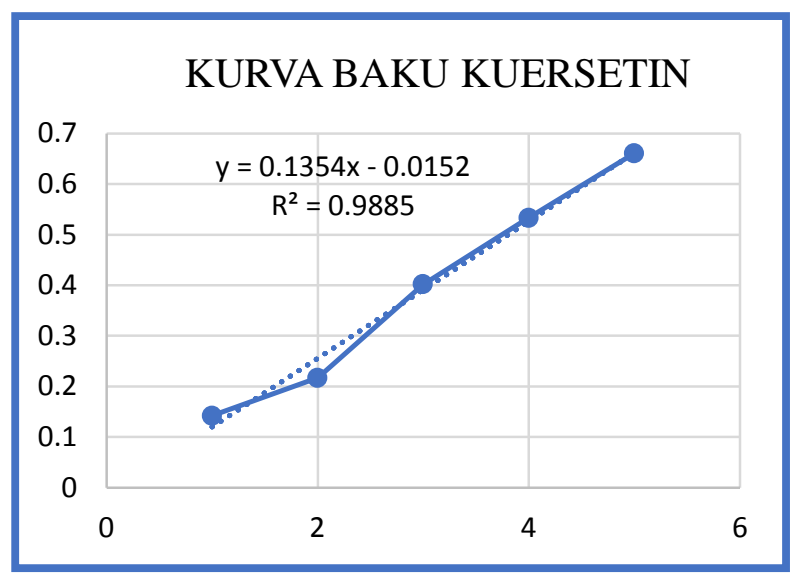

Gambar 2. Kurva Baku Kuersetin

\section{Hasil Kandugan Total Flavonoid}

Pada perhitungan Kadar Flavonoid Total Ekstrak Daun Gedi Hijau ini dihitung menggunakan Persamaan Regresi Linear Kurva Baku $\mathrm{y}=\mathrm{ax}+\mathrm{b}$ menghasilkan kandungan flavonoid pada Kota Bitung sebesar 2,64 $\mathrm{mg}$ QE/g ekstrak $\pm 0,035$, Minahasa Selatan 1,91 mg QE/g ekstrak \pm 0,027, Kotamobagu 4,84 mg QE/g ekstrak \pm 0,03, Minahasa Utara 4,40 mg QE/g ekstrak $\pm 0,091$, Manado 3,45 mg QE/g ekstrak \pm 0,012, Minahasa Tenggara $1,72 \mathrm{mg} \mathrm{QE} / \mathrm{g}$ ekstrak \pm 0,006, Minahasa 3,67 mg QE/g ekstrak $\pm 0,033$, Tomohon $3,40 \mathrm{mg}$ QE/g ekstrak $\pm 0,003$. Dan dari data diatas menunjukkan bahwa kandungan Total Flavonoid tertinggi berasal dari daerah Kotamobagu (Dataran Tinggi ) dengan nilai

kandungan flavonoid sebesar 4,84 mg QE/g ekstrak. Dataran tinggi merupakan dataran yang luas dan letaknya di daerah tinggi atau pegunungan yang tingginya berkisar $700 \mathrm{~m}$ di atas permukaan laut. Secara geografis jenis tanah di daerah ini merupakan Tanah Alluvial, tanah alluvial merupakan jenis tanah yang terbentuk dari hasil erosi dan sedimentasi sehingga cukup mendukung untuk bercocok tanam karena tanahnya sangat subur (Kasenda, dkk. 2014).

\section{Pembuatan Spektrum FTIR}

Spektrofometer inframerah merupakan suatu metode yang dapat mengukur secara cepat contoh tanpa merusak dan mampu menganalisis beberapa komponen secara serentak (Wold et al., 2001). Spektrum FT-IR daun gedi memberikan pola yang hampir mirip satu sama lain, hal ini menandakan bahwa senyawa kimia yang dikandung hampir sama.

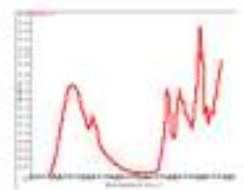

(a)

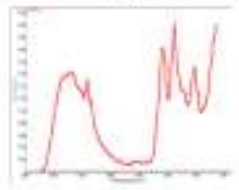

(c)

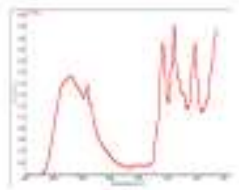

$|e|$

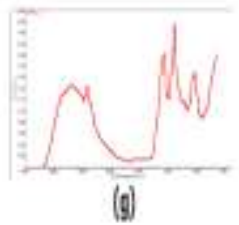

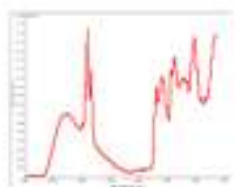

(b)

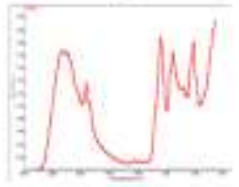

(d)

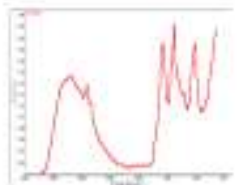

(if)

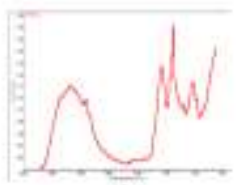

(b) 
Gambar 3. Spektra FTIR Daun Gedi Hijau

(a) Bitung, (b) Minahasa Selatan,

(c) Kotamobagu, (d) Minahasa

Utara, (e) Manado, (f) Minahasa

Tenggara, (g) Minahasa, (h)

Tomohon

Berdasarkan pengujian dari ke 8 sampel menggunakan instrument FT-IR, diperoleh puncak absorbansi pada panjang gelombang 3580,05 $\mathrm{cm}^{-1}-3649,76 \mathrm{~cm}^{-1}$ menunjukan gugus $\mathrm{OH}$ (alcohol), pada panjang gelombang $3392,69 \mathrm{~cm}^{-1}-3496.99$ $\mathrm{cm}^{-1}$ menunjukan adanya gugus NH ( Amina Sekunder). Pada ikatan $\mathrm{C}=\mathrm{O}$ (Aldehid) terlihat di panjang gelombang 1720,43$1739,99 \mathrm{~cm}^{-1}, \mathrm{C}=\mathrm{O}$ (keton) pada $1675-1725$ $\mathrm{cm}^{-1}, \mathrm{C}=\mathrm{O}$ (asam karboksilat) pada 1700$1725 \mathrm{~cm}^{-1}$. Adanya ikatan $\mathrm{C}=\mathrm{C}$ (alkena) pada panjang gelombang $1620 \mathrm{~cm}^{-1}-1680$ $\mathrm{cm}^{-1}$. Serapan di daerah 1400-1500 $\mathrm{cm}^{-1}$ menunjukan adanhya $\mathrm{C}-\mathrm{C}$ aromatic.

\section{Analisis Data}

Model kalibrasi multivariat dibuat dengan program Mini Tab menggunakan metode regresi PLS. Kalibrasi multivariat dengan metode Partial Least Square Regression (PLS) secara otomatis akan memberikan informasi spektrum yang khusus dan relevan dengan suatu sifat kimia dari model kalibrasi pada bilangan gelombang tertentu (Van der Vort et al., 1992). Pembentukan model prediksi flavonoid total dilakukan oleh PLS dengan melibatkan variabel $\mathrm{x}$ (hasil pengukuran FTIR) dan variabel y (data hasil analisis metode $\mathrm{AlCl} 3$ ). Kalibrasi dan validasi model diolah dengan teknik validasi silang. Model dapat digunakan bila memiliki nilai kesalahan (standar error calibration SEC, standar error of cross validation SECV atau standard error of prediction SEP) rendah dan nilai korelasi atau koefisien determinasinya tinggi (Miller and Miller, 2010).

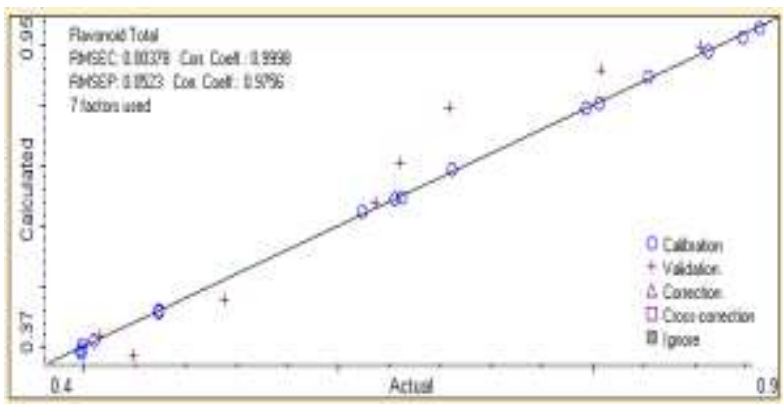

Gambar 4. Plot Regresi PLS Daun Gedi Hijau

Pada Plot regresi memperlihatkan mutu model regresi yang dihasilkan. Model data spektrum yang terbentuk merupakan model yang kurang baik karena menghasilkan titik yang tidak berdekatan satu sama lain, sehingga memperoleh nilai korelasi yang rendah.

Berdasarkan Hasil prediksi PLS menunjukkan nilai korelasi $(r)$ kalibrasi $=$ 0.999, nilai korelasi $(r)$ validasi $=0.975$ dan nilai $\mathrm{SEP}=0.052$ dan $\mathrm{SEC}=0.003 \mathrm{Hal}$ ini menunjukkan bahwa model kalibrasi dapat diterima dikarenakan memenuhi syarat dengan nilai koefisian determinasi yang tinggi dan galat yang rendah (Miller and Miller, 2010).

\section{KESIMPULAN}

1. Berdasarakan hasil Validasi Spektroskopi IR yang telah didapatkan menunjukkan bahwa Hasil tersebut memenuhi persyaratan dengan nilai parameterparameter $(r)$ validasi $=0.975$ dan nilai $\mathrm{SEP}=0.052$. Hal ini menunjukkan bahwa model Validasi dapat diterima 
dikarenakan memenuhi syarat dengan nilai koefisian determinasi yang tinggi dan galat yang rendah.

2. Berdasarkan hasil yamg di dapatkan bahwa hasil dapat di aplikasikan dalam penentuan kadar total flavonoid dengan menggunakan metode FTIR.

\section{SARAN}

Disarankan agar dalam penentuan kandungan total flavonoid menggunakan spektrofotomer FTIR dapat menggunakan metode kemometrik yang lain.

\section{DAFTAR PUSTAKA}

Harbone. 1987. Metode Fitokimia Penuntun Cara Modern Menganalisis. ITB press, Bandung.

Kasenda, Ivanny, M.Sylviah, dan H.Wungouw. 2014. Perbandingan Denyut Nadi antara Penduduk yang Tinggal di Dataran Tinggi dan Dataran Rendah. E-Biomedik, 2(2): 1-6.

Mamahit L.P. \& Soekarno,N.H., 2010. Satu senyawa organik yang diisolasidari daun gedi (Albemoschus manihot $\mathrm{L}$. Medik) Asal Sulawesi utara. Jurnal Kimia. Vol.3, No.1, Hal. 45.

Miller, J.N., and Miller, J.C. 2010. Statistics and Chemometrics for Analytical Chemistry Sixth edition. Pearson Education Limited, England.

Pine, A.T.D., Alam, G. dan Attamim, F. 2011. Standarisasi mutu ekstrak daun gedi (Abelmoschus manihot $\mathrm{L}$. Medik) dan uji efek antioksidan dengan metode DPPH. http://www.pasca.unhas.ac.id/jurnal. [21 Agustus 2012].

Robinson, T., 1991. The Organic Constituens of Higher Plants, 6th $E d$., Diterjemahkan oleh Kosasih Padmawinata, Penerbit ITB, Bandung

Rohaeti, E., Heryanto, R., Rafi, M., Kurniasari, I., and Darusman, L. K., 2006, Rapid Analysis of Total Flavonoids from Medicinal Herb: Interpretation of Chemometrics on Infrared Spectra of Phyllantus niruri, Prosiding of The 2006 Seminar on Analytical Chemistry 9 Maret 2006, Departemen Kimia Universitas Gadjah Mada, Yogyakarta.

South, E., H. Kaempe dan A. Tampi. 2013. Evaluasi Kandungan Total Polifenol dan Isolasi Senyawa Flavonoid Pada Daun Gedi Merah (Abelmoscus manihot L.). Chemistry Progress. 6 : 86.

Suryanto, E. 2012. Fitokimia Antioksidan. CV.Putra Media Nusantara, Surabaya. 